\title{
Reform and Effect Evaluation of Clinical Nursing Skills Training Teaching Model
}

\author{
Cuiling Tong ${ }^{1,2^{*}}$, Xiaowei $\mathbf{Q i}^{1^{*}}$, Aiping Gong1, Liping Li ${ }^{1}$, Hong Zhou ${ }^{1 \#}$ \\ ${ }^{1}$ School of Medicine, Yangtze University, Jingzhou, China \\ ${ }^{2}$ Jingzhou Vocational and Technical College, Jingzhou, China \\ Email: *1059634547@qq.com
}

How to cite this paper: Tong, C. L., Qi, X. W., Gong, A. P., Li, L. P., \& Zhou, H. (2020). Reform and Effect Evaluation of Clinical Nursing Skills Training Teaching Model. Open Journal of Social Sciences, 8 , $1-7$.

https://doi.org/10.4236/jss.2020.811001

Received: October 9, 2020

Accepted: November 6, 2020

Published: November 9, 2020

Copyright $\odot 2020$ by author(s) and Scientific Research Publishing Inc. This work is licensed under the Creative Commons Attribution International License (CC BY 4.0).

http://creativecommons.org/licenses/by/4.0/

\begin{abstract}
Objective: To explore the best mode and implementation effect of clinical nursing skills training. Methods: A total of 218 four-year nursing undergraduates from a school were selected as the research subjects, of which 125 were in the test group in 2013 and 93 were in the control group in 2012. Results: There was a statistically significant difference between the experimental group and the control group in the effect of training teaching and clinical decision-making ability $(p<0.01)$. Conclusion: The reform of clinical nursing skills training model has promoted the training effect, cultivated the clinical decision-making ability of nursing students, strengthened the close integration of knowledge, operation and clinical practice, and laid a good foundation for nursing students to enter the clinic.
\end{abstract}

\section{Keywords}

Clinical Skills, Practical Training, Reform

\section{Introduction}

Clinical nursing skills are an important part of the quality of nursing talents, one of the core abilities of nurse practitioners, and the necessary conditions and basic skills for nursing students to engage in nursing work (Chen et al., 2015; Fu \& Su, 2016; Gao et al., 2013; Li et al., 2019). The effectiveness of clinical nursing skills training and teaching not only affects the quality of nursing talent training, but also affects the quality of clinical nursing. It is essential for the rehabilitation of patients, improving the treatment of critical and critical illnesses, and reducing mortality (Chen et al., 2015; Gao et al., 2013; Li et al., 2019). The current 
clinical nursing skills training teaching overemphasizes the accuracy of operating procedures and the standardization of operating actions. Nursing students often only pay attention to the exercise of actions and do not pay attention to the training of thinking styles. After entering the clinic, they will face complex clinical scenarios. Demonstrate poor resilience and adaptability (Chen et al., 2015; Gao et al., 2013; Li et al., 2019; Huang et al., 2016). Therefore, this study aims to improve the clinical nursing skills and clinical decision-making ability of nursing students through the reform of the clinical nursing skills training model, shorten the distance between school teaching and clinical practice, and lay a good foundation for nursing students to enter the clinic.

\section{Objects and Methods}

\subsection{Research Object}

218 four-year nursing undergraduates from a school were selected as the research objects. According to the order of admission, 93 students from 3 classes in the 2012 grade were selected as the control group, and 125 students from 4 classes in the 2013 grade as the test group. There was no statistically significant difference between the two groups of students in age structure, gender, curriculum setting, and faculty allocation $(p<0.05)$, and they were comparable.

\subsection{Research Methods}

"Clinical Nursing Skills Training" is arranged in the last semester before entering the clinical practice, with a total of 32 hours. Comprehensive capabilities: Control group adopts traditional teaching: "Teacher's simple teaching + single-person single skill operation training + single-person single-item assessment" teaching mode (Zhang \& Huang, 2018); scores constitute $20 \%$ of attendance and $80 \%$ of individual operation assessment. Test group adopts the reformed teaching mode: "Teacher's simple teaching + clinical case-oriented single skill operation training combined with team comprehensive skills operation training + clinical case-oriented single assessment combined with team comprehensive assessment + assessment video analysis and summary" teaching mode (Chen \& Long, 2015; Lei et al., 2016; Zhang \& Huang, 2018). Achievements constitute attendance accounted for 5\%, individual operation assessment accounted for $45 \%$, case analysis $10 \%$, comprehensive assessment $30 \%$, comprehensive evaluation $10 \%$.

\subsection{Evaluation Method}

- Training effect evaluation table: evaluation content includes five aspects of training content, methods, conditions, teacher teaching, and self-evaluation. A three-level scoring method is adopted, namely "satisfied", "general" and "unsatisfied".

- Nursing clinical decision-making ability measurement questionnaire (Ye \& Jiang, 2005): The total score is 125 points, the reliability is 0.89 , and the validity is 0.94 .

- Investigation method. Before and after the training, the "Training Effect Evalu- 
ation Form" and the "Nursing Clinical Decision-Making Ability Measurement Questionnaire" were issued. Before and after the training, the test group issued a total of 125 questionnaires and 116 valid questionnaires, with an effective rate of $92.80 \%$; 93 before and after the training control group. 90 valid questionnaires, with an effective rate of $98.92 \%$.

\subsection{Statistical Methods}

The data was analyzed using SPSS19.0 statistical software package, the count data was analyzed by $\chi^{2}$ test, and the measurement data was analyzed by $t$ test.

\section{Result}

\subsection{The Two Groups' Evaluation of the Practical Teaching Effect}

It can be seen from Table 1 that, in addition to the self-evaluation, the test and the control group are not statistically different, the training content, methods, conditions, teacher teaching and overall evaluation of the experimental group are higher than those of the control group. The difference is statistically significant $(p<0.05)$ (Table 1$)$, indicating that the overall evaluation effect of the experimental group on teaching is higher than the control group.

\subsection{Comparison of Clinical Decision-Making Ability between the Two Groups before and after Training}

The clinical decision-making ability scores of the test group before training and the control group were not statistically different $(p>0.05)$. The clinical decision-making ability scores of the test group were better than the control group before training, and the difference was statistically significant $(p<0.05)$ (Table 2).

\section{Discuss}

A Clinical nursing skills are the necessary nursing ability for nursing students to enter clinical work, and it is an important guarantee for nursing students to enter the role as soon as possible after graduation and do a good job in clinical nursing work. Therefore, reforming the clinical skills training model is an important task to promote teaching effects and ensure the quality of nursing.

Table 1. Students' evaluation of the effectiveness of the training model (n, \%).

\begin{tabular}{ccccc}
\hline Project & $\begin{array}{c}\text { Control group } \mathrm{n}=90 \\
{[\mathrm{n}(\%)]}\end{array}$ & $\begin{array}{c}\text { Test group } \mathrm{n}=116 \\
{[\mathrm{n}(\%)]}\end{array}$ & $\boldsymbol{\chi}^{2}$ value & $\boldsymbol{p}$ value \\
\hline Training content & $69(76.67)$ & $106(91.38)$ & 8.581 & 0.003 \\
Training method & $67(74.44)$ & $109(93.97)$ & 15.522 & 0.000 \\
Training conditions & $61(67.78)$ & $99(85.34)$ & 9.018 & 0.003 \\
Teacher teaching & $79(87.78)$ & $111(95.69)$ & 4.428 & 0.035 \\
Self-evaluation & $76(83.33)$ & $105(90.51)$ & 1.753 & 0.186 \\
Overall evaluation & $70(77.78)$ & $106(91.38)$ & 7.535 & 0.006 \\
\hline
\end{tabular}


Table 2. Comparison of clinical decision-making ability between the two groups before and after training $(\bar{x} \pm s)$.

\begin{tabular}{|c|c|c|c|c|c|c|c|c|}
\hline \multirow[b]{2}{*}{ project } & \multicolumn{2}{|c|}{ Before training } & \multirow[b]{2}{*}{$t$ value } & \multirow[b]{2}{*}{$p$ value } & \multicolumn{2}{|c|}{ After training } & \multirow[b]{2}{*}{$t$ value } & \multirow[b]{2}{*}{$p$ value } \\
\hline & $\begin{array}{l}\text { Control group } \\
\qquad \mathrm{n}=90\end{array}$ & $\begin{array}{l}\text { Test group } \\
\mathrm{n}=116\end{array}$ & & & $\begin{array}{l}\text { Control group } \\
\qquad \mathrm{n}=90\end{array}$ & $\begin{array}{l}\text { Test group } \\
\mathrm{n}=116\end{array}$ & & \\
\hline Problem-finding ability & $22.25 \pm 3.31$ & $22.99 \pm 3.41$ & 1.556 & 0.121 & $26.66 \pm 4.78$ & $29.28 \pm 4.98$ & 3.828 & 0.000 \\
\hline Target ability & $7.78 \pm 2.06$ & $7.99 \pm 1.48$ & 0.805 & 0.422 & $9.16 \pm 2.16$ & $10.21 \pm 2.49$ & 3.193 & 0.002 \\
\hline Decision-making ability & $26.39 \pm 3.25$ & $27.00 \pm 4.69$ & 1.107 & 0.270 & $29.34 \pm 5.90$ & $33.02 \pm 4.95$ & 4.853 & 0.000 \\
\hline Ability to implement programs & $15.08 \pm 2.30$ & $14.53 \pm 2.65$ & -1.584 & 0.115 & $19.12 \pm 3.83$ & $19.18 \pm 4.58$ & 0.095 & 0.924 \\
\hline Evaluation feedback ability & $6.58 \pm 1.31$ & $6.76 \pm 1.24$ & 1.025 & 0.307 & $7.69 \pm 1.90$ & $8.31 \pm 1.41$ & 2.553 & 0.012 \\
\hline Total score & $78.07 \pm 6.88$ & $79.27 \pm 9.13$ & 1.031 & 0.304 & $91.97 \pm 13.23$ & $100.00 \pm 13.85$ & 4.206 & 0.000 \\
\hline
\end{tabular}

\subsection{The Reform of Clinical Nursing Skills Training Teaching Model Promotes the Effect of Practical Training}

The results of the study showed that the experimental group was better than the control group in terms of training content, training methods, teacher teaching and self-evaluation, and the overall satisfaction reached $91.38 \%$. The main reason is: traditional training teaching and assessment standards, centered on "skills", teaching and assessment methods are single, nursing students follow the steps to repeat the simulation, operation training and assessment are carried out on simulators without thought and emotional reactions. Teachers use harsh scoring standards to evaluate the assessment situation, so that the nursing students are not very motivated to learn, and they pay too much attention to the standardization and proficiency of skill operations. They cannot be well integrated with the clinical practice. The experience of the nursing students after entering the clinic is that the school teaching is different from the clinical practice, causing difficulty in entering the clinic (Xia et al., 2011). After the reform, the teaching model of practical training implements a three-in-one teaching model of theoretical penetration, thinking training, and practical training. It uses a combination of clinical cases and scenario simulation, a combination of real people and simulated people, and a combination of individual single items and team integration. The assessment method, teaching and assessment content, standards and clinical practice are closely integrated, avoiding the disconnection between assessment and clinical practice, strengthening the close integration of knowledge, operation and clinical practice, and ensuring the application of learning (Ma et al., 2015; Dou et al., 2017); advance the clinical adaptation period of nursing students, Shorten the process from nursing students to nurses, from school to clinic, stimulate nursing students' interest in learning, and promote the teaching effect.

\subsection{The Reform of Clinical Nursing Skills Training Teaching Model Is Helpful to the Cultivation of Clinical Decision-Making Ability of Nursing Students}

Clinical decision-making ability is an important part of the professional quality 
of nursing college students. Cultivating the clinical decision-making ability of nursing college students has become an important topic of contemporary nursing education (Hu \& Jiang, 2010). Studies have shown that the clinical decision-making ability of nursing students who adopts the reformed training mode is better than the control group of traditional training methods, because traditional training teaching pays too much attention to the training of hand movements of nursing students and does not pay attention to the training of thinking style (Fang et al., 2016), reform. The subsequent training and teaching is oriented by clinical cases. While paying attention to the teaching content, teachers pay attention to creating teaching scenarios for clinical problems. The selected cases are from clinical internal, external, gynecological, and pediatric common diseases and frequently-occurring diseases. During the training and assessment, nursing students conduct clinical scenario exercises through clinical case analysis, and learn to comprehensively use the knowledge and skills they have learned to discover, analyze and solve problems; at the same time, after the assessment, the teacher guides the nurses to watch the assessment video, discuss and evaluate, observe the strengths and weaknesses of each nursing student and team assessment, and then the teacher analyzes and summarizes, so as to cultivate the comprehensive ability of nursing students in clinical decision-making, practical hands-on and teamwork (Guo et al., 2012; Ma et al., 2015).

\section{Conclusion}

During the training and assessment, nursing students conduct clinical scenario exercises through clinical case analysis, and learn to comprehensively use the knowledge and skills they have learned to discover, analyze and solve problems; at the same time, after the assessment, the teacher guides the nurses to watch the assessment video, discuss and evaluate, and observe the strengths and weaknesses of each nursing student and team assessment, and then the teacher analyzes and summarizes, so as to cultivate the comprehensive ability of nursing students in clinical decision-making, practical hands-on and teamwork. There are still some problems in the implementation of this research, such as training conditions to be optimized, training methods and content to be continuously improved, etc., which need to be further summarized, explored and studied in the future.

\section{Acknowledgements}

We thank the Scientific Research Fund Project of Jingzhou Science and Technology Bureau of Hubei Province (Fund Number: 2014-85), and School-level key teaching research project of Yangtze University (fund number: JY2014015). Prof. Zhou, H. put forward meaningful comments on the manuscript, and reviewers for their important suggestions. Prof. Zhou, H. published several articles in important domestic journals on the research of nursing skills training model for clinical decision-making ability training, and after using the reform in the 
teaching of undergraduate and postgraduate nursing in our school, we obtained clinical nursing skills training teaching model, achieved good results and increased student satisfaction.

\section{Conflicts of Interest}

The authors declare no conflicts of interest regarding the publication of this paper.

\section{References}

Chen, H. L., \& Long, S. L. (2015). Application of Comprehensive Assessment Method in "Fundamental Nursing" Experimental Teaching. Chinese Nursing Research, 29, 1351-1352. (In Chinese)

Chen, Z. S., Huang, H. G., \& Wu, K. S. (2015). Practical and Scientific Inspection of Clinical Ability Evaluation Index System of Nursing Students in Secondary Vocational School. Chinese Nursing Research, 29, 3281-3284. (In Chinese)

Dou, L., Wang, X. Z., Sun, J. J., \& Nie, Y. Q. (2017). Application of CDIO Teaching Mode on Comprehensive Nursing Practice of Higher Vocational Nursing Students. Journal of Nursing Administration, 17, 365-367. (In Chinese)

Fang, H. P., Liu, H. J., \& Chen, Y. Y. (2016). Application of Progressive Teaching Mode in Training Student Nurses' Basic Nursing Skills. Journal of Nursing Science, 31, 78-80. (In Chinese)

Fu, X. L., \& Su, Y. L. (2016). Construction of a Evaluation System of Basic Nursing Skills for Higher Vocational Nursing Students. Chinese Journal of Nursing Education, 13, 662-666. (In Chinese)

Gao, H. L., Ren, Y. Q., Li, H. M., Xue, J. J., \& Lan, S. Y. (2013). Construction of Scoring Guide Lines for Clinical Nursing Procedures and Their Application in Nursing Teaching. Journal of Nursing Science, 28, 73-75. (In Chinese)

Guo, L. L., Tang, G. W., Fu, Y., Li, G. H., \& Zhao, W. P. (2012). Research and Practice on CDIO-Based Application-Oriented Practical Teaching System of Computer Major. IERI Procedia, 2, 24-29. https://doi.org/10.1016/j.ieri.2012.06.046

Hu, K. Q., \& Jiang, X. L. (2010). Study on Clinical Decision-Making Ability of Baccalaureate Nursing Students and Its Related Infect Factors. Journal of Nurses Training, 25, 198-200. (In Chinese)

Huang, F., Li, M. L., Xiong, L. S., Zhao, L. L., \& Liu, S. L. (2016). The Reform of Nursing Education Directed by Nursing Skills Competition. Chinese Journal of Nursing Education, 16, 511-514. (In Chinese)

Lei, X., Wang, Z., \& Xiao, S. X. (2016). The Influence of Case-Led Cooperative Learning Mode on Clinical Thinking Ability of Nursing Students. Chinese General Practice Nursing, 14, 192-194. (In Chinese)

Li, M. L., Fang, J. B., Liu, L., \& Li, Y. (2019). Research Advances on Direct Observation of Procedural Skills in the Application of Nursing. Chinese Nursing Research, 33, 2105-2108. (In Chinese)

Ma, W. G., Chen, J. L., Liang, T., Guo, A. M., \& Zhang, H. (2015). Application of Simulation-Based Objective Structured Clinical Examination in Comprehensive Ability Evaluation of Nursing Students before Graduation. Journal of Nursing, 22, 5-7. (In Chinese)

Xia, H. L., Jiang, Y. Y., \& Zhao, X. R. (2011). Application of Case-Based Assessment Me- 
thod in the Experimental Teaching of Fundamentals of Nursing. Chinese Journal of Nursing Education, 8, 13-15. (In Chinese)

Ye, X. C., \& Jiang, A. L. (2005). Development of AnInstrument for Measuring the Clinical Decision Making Ability of Nursing Under Graduates. Nursing Journal of Chinese People's Liberation Army, 22, 12-18. (In Chinese)

Zhang, X. X., \& Huang, F. (2018). Case Study as Leading-In in Nursing Skill Teaching for Nursing Undergraduates. Journal of Nursing, 25, 10-14. (In Chinese) 